\title{
THE CLOSED BOOTH
}

\author{
by Edwin M. Hanson
}

It has been said, about the language laboratory, as well as about other instutions, that the more it changes the more it remains the same. There are, at least, ambivalent reactions to the phenomenon entitled "Language Laboratory," but, among others, there is a single epiphenomenon which can, perhaps should, be dealt with, with the remedy at hand. The discussion set forth below, is intended to challenge an established practice and to create conviction favorable to making a change. We are concerned here with the improvement of a pedagogical device, the design of the language laboratory booths, which calls for an initial expenditure somewhat above that required for the type of open booth, many varieties of which are in current use in most other labs.

In the discussion which follows, an open booth is understood to refer to any type of partial enclosure which permits the free flow of air, either at the top, and/or the rear, from one student position to another. Closed booths, on the other hand, are those which are totally walled-in, with a windowed door at the rear, supplied with air or conditioned air from a sufficiently distant plenum to reduce sound of voices from other booths $-40 \mathrm{db}$, or subjectively, below notice. The point of difference indicated here between the open and the closed booth is a pragmatic rather than an absolute one. The closed booth in this definition is not taken to mean one which is acoustically sealed from all sound but rather one in which, due to the sound-seepage being sufficiently suppressed, the student will feel confident that his own responses are not intruding into the work of others.

There would be no need, on this score at least, for the closed booth if it were possible to arrange for sound-sealing earphones and limited pick-up microphones. There are, it is true, both of these on the market; but in actual use when a student (or two or more) begins to make his normal responses others hear them through their microphones and consequently adjust by lowering their voice level-and so does he. This phenomenon is observable in all language laboratories which use the open booth, as a kind of servo unit in operation. After a very brief time all students are either speaking softly, or mumbling, or not responding at all. All heads turn when any student makes normally loud sounds.

This problem can be dealt with, and has been, by the teacher insisting on loud responses by all, letting the chips fall where they may. 
The distractions, it has been said, are actually beneficial since the student is forced by extra effort to overcome the surrounding noises, and the resulting exercise of the vocal apparatus strengthens the learning. It is readily granted that this approach may have real merit, that perhaps careful studies should be made to determine the effects. A serious objection, however, arises when this type of lab use is presented as a reason in favor of the construction of open booths. It is rather the reverse of the reasoning that is true: if open booths are used, the students must raise their voices. In a closed booth, however, distracting noises (voices or any kind of noise) $c a n$ be introduced, if it is found advisable, but the choice is then under the control of the teacher or the method.

Another alternative, also accepted by some foreign language teachers, is that it really does not matter very much whether the student voices firmly or sotto voce. Here again, construction plans ought not be formulated on a practice which has been derived from actual limitation imposed by the open booth. Students may make low level or no responses in a closed booth. But a far larger number of teachers express a strong preference in favor of the normal or louder than normal response.

We can cite an authoritative voice on this point in an exerpt from Language Laboratory Learning by Professor Fernand L. Marty, A. V. Publications, Wellesley, Massachusetts, 1960. page 218:

Why individual rooms instead of booths?

1. The students prefer to work in the privacy of a room.

2. In a room, the student can speak in a natural voice. In a booth, unless he whispers into the microphone, he disturbs (and is disturbed by) the students in the adjoining booths. Whispering is not natural-in fact, it is harmful; the students acquire bad habits in muscular tension, rhythm, intonation, timbre of the vowels.

3. In a room, the student is not disturbed by surrounding noises. In a booth, he is disturbed by the noise of people coming and leaving, the chairs being moved, the doors being opened and closedl, etc. Close-fitting headphones protect only when the student is listening since when he is recording his microphone picks up all surrounding noises and sends them to his headphones.

4. It is difficult to give an examination in a booth laboratory because the students can hear each other. 
5. For most students, listening to a loud-speaker is more natural more lifelike, and less tiring than wearing headphones. Working with headphones may be harmful because the seudents get used to understanding the foreign language from headphones and they may find it more difficult to understand a live voice.

6. Headphones present problems of hygiene. Some students may rightly object to having to use headphones which have been worn by students with dirty hair or skin diseases.

7. Headphones may become sticky and uncomfortable.

Add to this list from our own experience: mechanical failure of the headset, with repair and replacement costs which are time consuming and expensive. After only three years, not one of our headsets/ microphones remained in use without repairs, even though they were of excellent quality and purchased at a price of $\$ 60$. each from a very prominent American company.

Now, this feature (hearing one's own voice the way others hear it) has been highly touted as the best means for informing the student of the closeness of his response to the model. It can be stated with confidence, though with deference to the long held contrary belief, that by using any carphones at all the student is prevented from acquiring the voice-ear control which he will need at all times when he is not in the language laboratory. It is useful for him to compare his response with the model, and this can be accomplished by recording and immediate playback (the so-called "responser" technique); but no one ought to believe that any student is capable of iimultaneous comparison. It is precisely this type of frustration which has been at least partly responsible for some attrition in the use of the laboratory. When the student removes the headphones, leaves the lab, then goes to the classroom where his teacher asks him to respond in the foreign language, he quite suddenly discovers that his hour in the lab has not prepared him for the normal voice control which he usually gets from his ears.

This phenomenon of ear-voice interference has been deprecated as of small consequence by a few teachers on first hearing of it. It is not used here as the principal reason for the use of closed booth. But taken together with the number of other present difficulties which can be obviated or solved altogether, the closed booth is recommended as a means for improving the learning environment for foreign language study in a significant way.

Administratively, the closed booth fares quite well compared to present language laboratory design. Mention has not been made of the 
increase in concentration levels together with the concommitant longer attention-span when a student is not distracted, aside from the usual room noises, by the presence of an observing (and observing) monitor. With all students in closed booths none can be seen by the teacher, but each (or all) can be heard from a teacher's console, which, in the present plan, can be simply one of the closed booths. When correction is necessary, the teacher is able to discuss the problem with the individual student, without any intrusion of sight or sound into the work of any other. The teacher, having determined which students require assistnace by having listened to their (normally loud) responses, steps over to the booth and discusses the problem face-to-face, in person, and close enough to see and be seen. This is a clear improvement over the present practice of essaying correction via transmission, and at a distance. The usual teacher's console is now placed at the front of the lab room, so that vision is adequate for row 1 and perhaps row 2 , but those seated beyond would need telescopes in order to see the mouth, tongue position etc. being demonstrated by the teacher from her desk. If the teacher steps over to the student quietly and attempts to supply corrective demonstrations, she can hardly avoid being noticed, and the ensuing conversation is often superfluous, and may well be deleterious, to the progress of others in the room.

In conclusion, Michigan will not be the first to use closed booths. Middlebury College, Vermont, is a well known language school and uses closed booths exclusively. Adrian College, Adrian, Michigan, has installed twenty closed booths, and the University of Illinois is planning a new language laboratory with closed booths. And there are others. In view of curriculum innovations which may well move in the direction of individual-study plans, the closed booth will be the only really suitable means for an adequately isolated study environment.

Are the booths large enough? With the arrival of assorted teaching machines, visual equipment of many types, etc., will the closed booth become over-crowded? No, it can be stated with reasonable confidence, under the equipment being planned for use in the new lab. The final design is still not quite decided upon in precise detail, but at least it is known that the equipment needed for installation within each booth will be strictly limited to a speaker, a microphone, a button selector similar to that used on the push-button telephone, with a volume control mounted on a small console or recessed into the desk-top, and provision for a video outlet.

Remote location of all devices which may be required makes possible ease of maintenance, reduction of break-downs due to mis-handling, 
and economies in use. The computer-operated system which has been designed for the distribution of programs will have capabilities for transmitting audio and visual materials in a variety of ways to which a limit has not been established since it is associated with the limitations of the computer itself. The system will operate with either the closed or the open booth, of course; however, dictates of taste and a sense of proportion will favor the utilization of sophisticated programs under the controlled conditions and in the privacy of individual closed booths.

Careful consideration has been given to the question of costs. The largest single economy will be reduction to zero in outlay for earphones. This will effect a savings, using a fair figure for purchase $(\$ 50$.$) and a$ reasonable period for replacement ( 5 years), in ten years of $\$ 25,000$, at the end of which period another $\$ 12,500$ will be needed. This assumes the number of open booths will be 250, instead of the 168 closed booths which can be built in the same space. The one-time purchase price of booth equipment for the closed booth, including console, speaker, and microphone, but not including video equipment, is $\$ 100$. each, or $\$ 16,800$. Conduit, wiring, labor costs are the same for both. Booth construction is only slightly higher, even considering the doors and knobs and hinges. There remains the single important added expense of the airducts. Construction costs are not at hand at this time but the temptation is strong to equate them with the savings in earphones.

There remains the question of sufficiency in the number of closed booths, 168. If a system of registration is set up so that each student is assured of two full hours of use each week, the highest total tumber of student users will be 7,051 based on a weekly operating schedule of 84 hours, which is the number of hours per week the present lab is open. Some departments may require more, some less. Expansion space is provided for in the building plans. Dormitory labs can be extended. It is also within the realm of possibility that students will find that the conducted increase in levels of concentration in the closed booth will lower the time spent in the lab while increasing the amount of learning.

Although the reasoning in the foregoing paragraphs was meant to apply to colleges and universities, a number of statements could be made in favor of using closed booths in the high schools. Teachers ought by now to have realized that having the class "under her eye" is no guarantee that studying and learning is in fact going on. Indeed, the isolation of students may well be the single most salutory improvement in language laboratory use. 
With reference to the use of very good sound-isolating earphones in conjunction with limited pick-up microphones, it was stated that interferencc would nevertheless occur. But, let it be granted for the moment that a uscable level of isolation could be established in the open booth with headsets and microphones, so that, in effect, students could feel free to voice their responses at normal levels without inhibiting factor of cross-interference. The student makes his response; his voice is picked up by his microphone and travels, via wire, pre-amplifier, amplifier, and wire-lightning fast-back to his earphones; his ears perceive no time-lag, it is as though he hears himself as he speaks. And it is quite true that the voice-sounds which arrive at his ears quite effectively arrive there at a reduction in time-lag so great that no objection can possibly be raised to characterizing the phenomenon as 'simultaneous".

But what voice does he hear? His own? Yes,-and no. If by "his own voice" is meant the sound which the student himself has uttered, then of course it is his own. The use of a microphone in conjunction with earphones has long been established as an absolute necessity, due to the recognized need for self-modulation, or voice level control. If ears are shut off from hearing, as by placing cupped hands over them, or by wearing simple headphones, it becomes impossible to speak, or extremely difficult. This has been the reason for the introduction of the microphone. It permits the student to control the loudness level of his vocal response. However, the voice which he hears coming into his earphones, via the electronic train, is actually the voice which others hear, coming as it does when he is conversing outside of the laboratory, from his mouth and traveling to their ears. But while he is in the lab and wearing earphones his own ears are, in effect, their ears. He does not hear his own normal voice in the normal way he does when he speaks without the earphones covering his ear. 